\title{
Study of mould hardness for alpha set type resin bonded moulding sand system using Taguchi approach for metal casting applications
}

\author{
Deshpande Anand ${ }^{1}$, Gharge Aishwarya ${ }^{2}$, Deshpande Pratik ${ }^{2}$, Patil Pratik $^{2}$, Vaidya \\ Tejashree ${ }^{2}$ and Chate Ganesh ${ }^{1 *}$ \\ ${ }^{1}$ Dept. of Mechanical Engineering, KLS Gogte Institute of Technology, Belagavi, Affiliated to \\ Visvesvaraya Technological University, Belagavi, Karnataka, India \\ ${ }^{2}$ Dept. of Industrial and Production Engineering, KLS Gogte Institute of Technology, Belagavi, \\ Karnataka, India, Affiliated to Visvesvaraya Technological University, Belagavi, Karnataka, India
}

\begin{abstract}
The quality of the castings are depended on many properties of sand mould like mould hardness, green compression strength, shear strength etc. and these properties in turn dependent on factors such as grain fineness number of sand, setting/curing time, amount of resin, amount of hardener, moisture content etc. Mould hardness is very important while transferring mould from moulding station to pouring station when the weight of the mould is above $100 \mathrm{~kg}$ and may lead to defects. In the present work, an effort is made to study the mould hardness of a moulding sand specimen using Taguchi technique.L9 orthogonal array is used and experiments are conducted randomly. The main factors such as the amount of resin, amount of hardener and setting time were considered. Factors were selected based on Literature review and brainstorming session with foundries. The chemical (resin and hardener) used is alphas set type two part system. From experiments, it was observed that the Amount of resin and setting time are significant for mould hardness. Confirmation tests were conducted to validate the obtained results.
\end{abstract}

\section{Introduction}

Casting is the most basic manufacturing process to manufacture the engineering products made up of metals. There are many types of castings like sand casting, shell moulding, injection moulding etc. But sand casting is the widest method adopted to make cast products. Based on the type of sand and binding agents used, sand casting is again divided into the green sand moulding, chemicals and moulding, dry sand moulding, no-bake sand moulding, cold box moulding. Many researchers worked in the field of sand moulding and also tried to optimize the moulding sand system used for making moulds using different techniques. Rasik et al. used Taguchi technique to optimize process parameters in sand casting [1].Danko et al. investigated the properties of the reclaimed sand for making nobake sand moulds using alpha set binding system by using newly reclamation

\footnotetext{
* Corresponding author: ganeshchate@git.edu
} 
apparatus[2].Himanshu et al. used oil urethane no-bake binder system and used Taguchi technique to optimize the process, shrinkage of the specimen is taken as the response[3].Raghwendra et al. used Taguchi technique for green sand moulding sand to get effective and economical castings[4].Parappagoudar et al., used full factorial design to obtain a linear model for green sand moulding system[5].Dietert et al. emphasized that density of sand mould increases with mould hardness as a result of wide range of grain size [6].Sand drop defects in casting are influenced by mould hardness and also shear strength, which in turn is dependent on by grain fineness number (GFN), the quantity of binder (resin and hardener), curing time, the degree of ramming pouring velocity and so on. Barlow et al. studied the influence of hardness to prevent the mould wall movement in moulding[7]. Frost et al. analyzed pressure and hardness distributions in sand moulds using theoretical and experimental methods. The authors observed that frictional interface between moulding sand and pattern to be the governing factors that significantly affect mould hardness[8].From the above literature, it is understood that not much work is being done on Alpha set type sand mould systems and also mould hardness is highly influenced by the process variables. Proper control of process parameters and setting these process parameter is essential to get good quality castings i.e., castings with less sand drop defect. The present work focused on determining the optimum levels of process parameters to better mould hardness. Not much work reported yet to obtain optimum levels for a process. Taguchi method has been reported to reduce the process variation through a robust DOE to gain high-quality products at low costs. Taguchi method uses orthogonal arrays to decide the design matrix for experiments, determine the optimal process parameter setting for each response, and estimate the percentage of contribution of each individual factor towards the response [9].Taguchi method has been employed to determine the optimum input parameter levels on different quality characteristics (that is, outputs) of squeeze casting process[10], drilling[11], injection moulding process[12], cold box core shooter machine[13].From the above literature, it was understood that Taguchi technique reduces experimentation cost and time. Hence Taguchi technique was used for this study.

From the literature survey and also brainstorming session with foundries, the problem was defined. Most of the industries add resin and hardener to the sand by trial and error basis, hence at the beginning of the shift moulds start braking and gradually the workers increase the hardener and resin percentage. But too much of hardener and resin leads to difficulties in shakeout operation and also the gases evolved after pouring the molten metal will be entrapped because of the reduction in permeability. Hence it was decided to set the process parameters for mould hardness for the alpha-set type no-bake sand system.

The objectives of the work are

1. To set the levels of process parameters that affect the mould hardness.

2. To identify the factors which are significant for mould hardness.

3. To study the effect of hardener, resin, curing time and interaction between these parameters using an L9 orthogonal array on alpha set type no base moulding sand system.

\section{Materials and equipment used}

The work deals with chemically bonded moulding sand system. Sand is the main component in the system, a fresh silica sand with grain fineness number (GFN) number 5560 was taken, that is the medium sand. If coarse sand was taken, dimensional accuracy and surface finish of the casting will be compromised. If too fine sand was taken, it will reduce the permeability of mould and leads to blowholes and pin holes. The fresh sand is heated in sun rays in order to remove the moisture traces in the sand. The alpha set type no-bake twopart system resin and hardener were taken for the study. An Ester Cured Alkaline Resin 
binder (Commonly known as Alpha-set Resin).Alpha set chemicals are alkaline Phenolic systems and are eco-friendly, and gives good Casting Finish. As per industrial standards, the amount of resin (part A) to be added is from $1.8 \%$ to $2.2 \%$ weight of sand and amount of hardener(part B) is 20 to $22 \%$ weight of the resin. The fishbone diagram for mould hardness is as shown in fig 1 . There are many factors that affect the mould hardness. The factors which can be practically controlled easily, effectively and economically were considered. The factors and levels considered for experimentation are shown in Table 1.The values of levels and also the ranges are chosen based on the consultation with industry experts and also literature available.

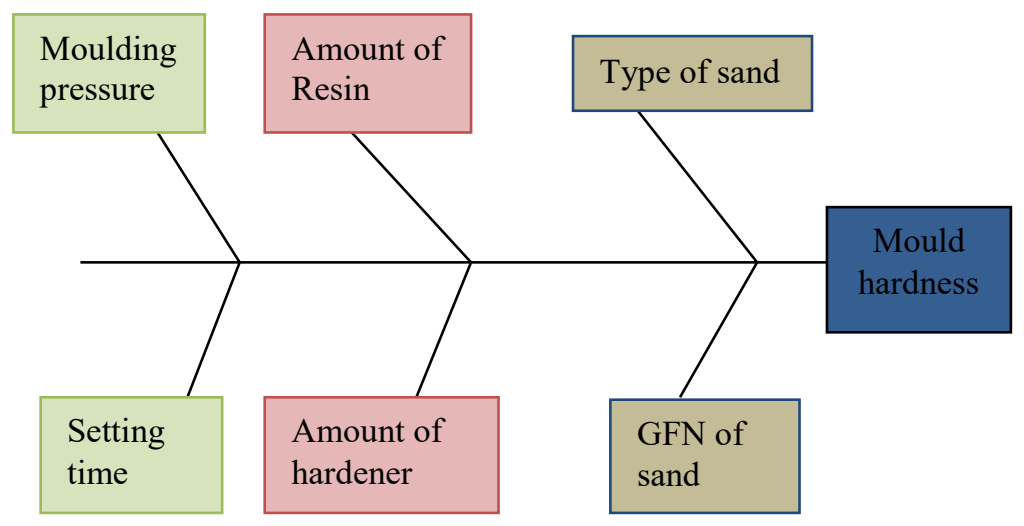

Fig. 1. Fishbone diagram for mould hardness

The measured quantity of sand is mixed with metered quantity resin and hardener using sand muller. 2 minutes of mixing (mulling) is done. The experiments were conducted using an L9 orthogonal array, as there were 3 factors and at 3 levels.

Table 1. Process parameters (factors) and their levels

\begin{tabular}{|c|c|c|c|c|c|}
\hline \multirow{2}{*}{ S.No } & Parameters & \multirow{2}{*}{ Notations } & \multicolumn{3}{|c|}{ LEVELS } \\
\cline { 3 - 6 } & & & 1 & 2 & 3 \\
\hline 1 & Resin (\% weight of Hardener ) & A & 1.8 & 2 & 2.2 \\
\hline 2 & Hardener (\% weight of Resin) & B & 20 & 22.5 & 25 \\
\hline 3 & Curing time(Mins) & C & 60 & 180 & 300 \\
\hline
\end{tabular}

The GFN of the sand to be used is confirmed by using sieve shaker, then the silica sand is dried by keeping it in sun rays for about 1 hour. $1 \mathrm{~kg}$ of sand is weighed and added in sand muller along with the resin and hardener. The quantity of resin and hardener are varied as these are considered to be factors. The variation is done on the basis of experimental design matrix as shown in Table 2. 
Table 2. Standard L9 orthogonal array and variable settings

\begin{tabular}{|c|c|c|c|c|c|c|}
\hline & \multicolumn{3}{|c|}{ DESIGN MATRIX } & \multicolumn{3}{c|}{ VARIABLE SETTINGS } \\
\hline S.No & $\mathrm{A}$ & $\mathrm{B}$ & $\mathrm{C}$ & $\mathrm{A}$ & $\mathrm{B}$ & $\mathrm{D}$ \\
\hline 1 & 1 & 1 & 1 & 1.8 & 20 & 60 \\
\hline 2 & 1 & 2 & 2 & 1.8 & 22.5 & 180 \\
\hline 3 & 1 & 3 & 3 & 1.8 & 25 & 300 \\
\hline 4 & 2 & 1 & 2 & 2 & 20 & 60 \\
\hline 5 & 2 & 2 & 3 & 2 & 22.5 & 180 \\
\hline 6 & 2 & 3 & 1 & 2 & 25 & 300 \\
\hline 7 & 3 & 1 & 3 & 2.2 & 20 & 60 \\
\hline 8 & 3 & 2 & 1 & 2.2 & 22.5 & 180 \\
\hline 9 & 3 & 3 & 2 & 2.2 & 25 & 300 \\
\hline
\end{tabular}

The mixture is then taken out from the muller and standard specimens are prepared using standard rammer. The specimens are allowed to settle for the predefined time (settling time) as per the experimental design matrix. The mould hardness is then measured using mould hardness tester. The step by step procedure is shown in Fig. 2.
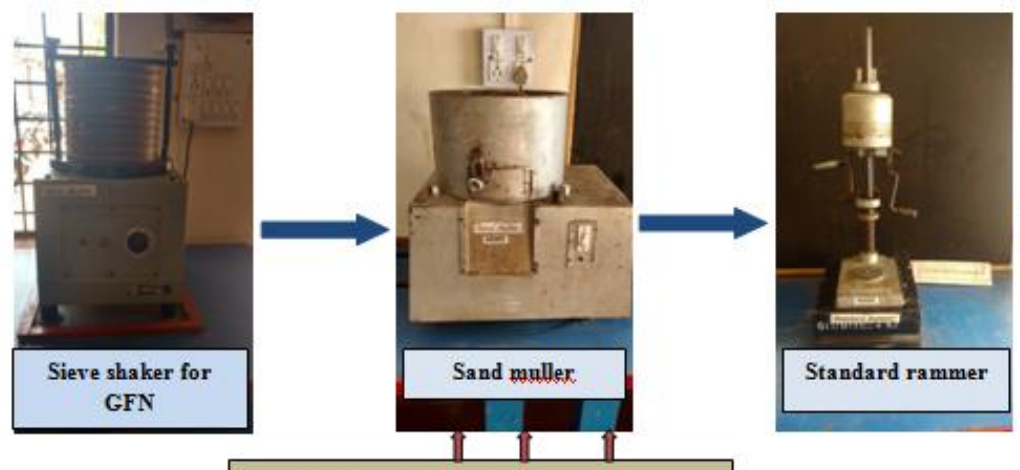

Fresh Silica sand + Resin + Hardener

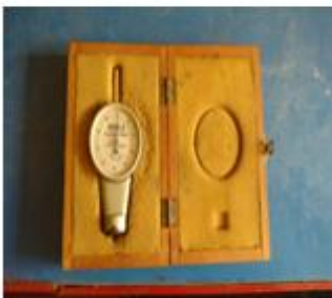

Mould hardness Tester
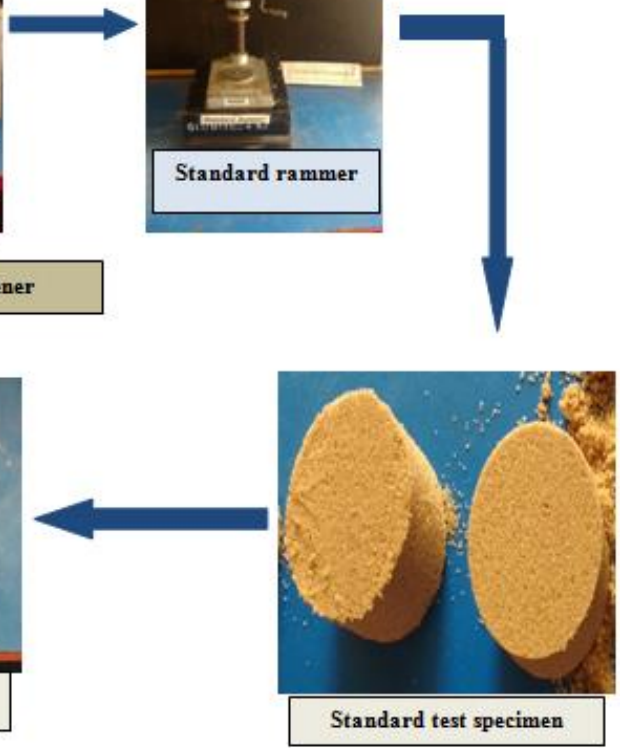

Fig. 2. Stepwise représentation of expérimentation 


\section{Results and Discussion}

The mould hardness (MH) is measured for 3 replicates. The average or mean value of all 3 replicates along with the signal to noise ratio are shown in Table 3.Eqution 1 is used to find a signal to noise ratio. Larger the better condition is used to find a signal to noise ratio, as mould hardness should be maximum (objective is to maximize).

Signal to noise ratio(Larger is better) $=-10 \log _{10} \frac{\left(\sum \frac{1}{Y_{i}^{2}}\right)}{n}$

Table 3. Experimental design matrix, mean value along with signal to noise ratio

\begin{tabular}{|r|l|r|r|r|r|r|r|}
\hline $\begin{array}{l}\text { Resin } \\
\text { (\%wt.of } \\
\text { sand) }\end{array}$ & $\begin{array}{l}\text { Hardener } \\
\text { (\%wt.of } \\
\text { resin) }\end{array}$ & $\begin{array}{l}\text { Setting } \\
\text { time } \\
\text { (hrs) }\end{array}$ & MH1 & MH2 & MH3 & $\begin{array}{l}\text { Signal to } \\
\text { noise } \\
\text { ratio(S/N) }\end{array}$ & Mean \\
\hline 1.8 & 20 & 1 & 58 & 59 & 59 & 35.36 & 58.66 \\
\hline 1.8 & 22.5 & 3 & 60 & 62 & 64 & 35.83 & 62 \\
\hline 1.8 & 25 & 5 & 67 & 67 & 66 & 36.47 & 66.66 \\
\hline 2 & 20 & 3 & 65 & 67 & 65 & 36.34 & 65.66 \\
\hline 2 & 22.5 & 5 & 71 & 70 & 72 & 37.02 & 71 \\
\hline 2 & 25 & 1 & 60 & 60 & 60 & 35.56 & 60 \\
\hline 2.2 & 20 & 5 & 72 & 73 & 73 & 37.22 & 72.66 \\
\hline 2.2 & 22.5 & 1 & 62 & 63 & 61 & 35.84 & 62 \\
\hline 2.2 & 25 & 3 & 66 & 67 & 66 & 36.43 & 66.33 \\
\hline
\end{tabular}

ANOVA test for the signal to noise ratio of mould hardness is given in Table 4 represents the signal to noise ratio. From the table, it can be inferred that resin and setting time are significant factors for mould hardness. Even though hardener acts as a catalyst, it does not play a significant role for mould hardness. The error in the ANOVA table indicates the interaction among the factors.

Table 4. Analysis of Variance for SN ratio

\begin{tabular}{|c|c|c|c|c|c|c|}
\hline Source & $\begin{array}{c}\text { Degrees } \\
\text { of } \\
\text { Freedom }\end{array}$ & $\begin{array}{c}\text { Sum of } \\
\text { squares }\end{array}$ & $\begin{array}{c}\text { Adjusted } \\
\text { Mean } \\
\text { Squares }\end{array}$ & F-test & P-test & $\begin{array}{c}\text { Percentage } \\
\text { contribution }\end{array}$ \\
\hline $\begin{array}{c}\text { Resin (\%wt.of } \\
\text { sand) }\end{array}$ & 2 & 0.578 & 0.28933 & 80.36 & 0.012 & 17.91 \\
\hline $\begin{array}{c}\text { Hardener } \\
\text { \%wt.of resin) }\end{array}$ & 2 & 0.035 & 0.01785 & 4.96 & 0.168 & 1.11 \\
\hline Setting time (hrs) & 2 & 2.606 & 1.30322 & 361.96 & 0.003 & 80.86 \\
\hline Residual Error & 2 & 0.007 & 0.00360 & & & 0.22 \\
\hline Total & 8 & 3.22801 & & & & 100 \\
\hline
\end{tabular}

The interaction of the factors is also not significant as per the ANOVA table. The highest percentage contributing factor is setting time followed by the amount of resin.Fig3.shows the fitted values that are the theoretical values and residuals(i.e., the difference between experimental values and fitted values).It also shows the variation in the residuals in all experiments and also the upper and lower range fitted values from zero residual. The residual is the difference between theoretical value and experimental value. The residual 
values fall +0.4 below and -0.2 below fitted (theoretical value). The residual for all the experiments are also shown in Fig. 3.
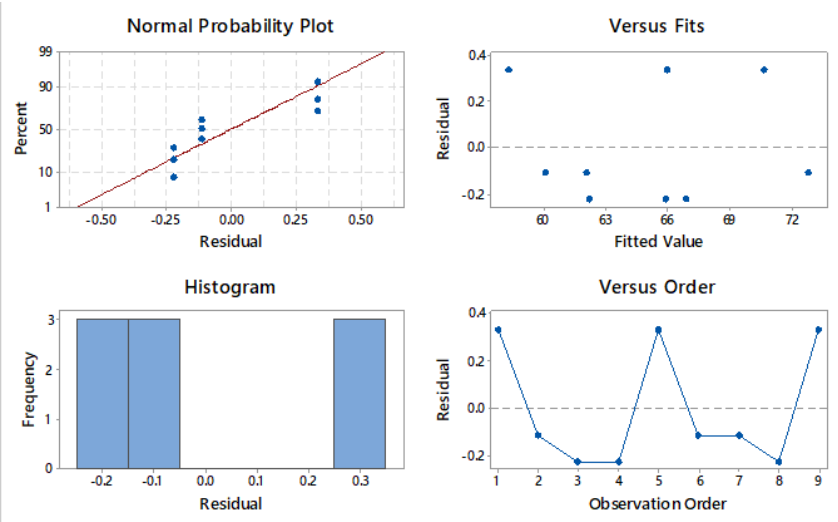

Fig. 3. Fitted values and residual plots

Fig. 4 is a graph of signal to noise ratio v/s factors. This graph shows the variation in signal to noise ratio with respect to different levels of the factors (process parameters). The highest point from the graph is considered to be the optimum levels of factors.

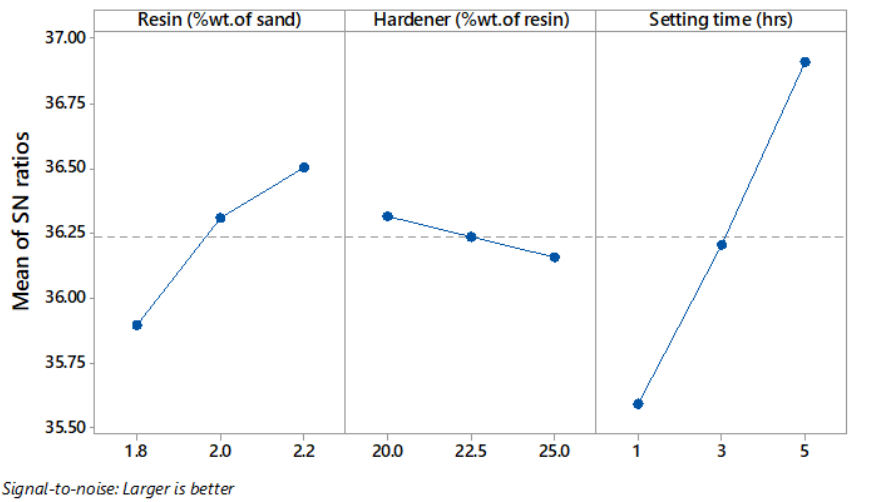

Fig. 4. Main effect plots for $\mathrm{SN}$ ratios v/s factors

The optimum process parameters can also be set by using a graph of mean v/s factors as shown in Fig. 5. As a number of resin increases mould hardness increases, it is because the resin is the binding agent. As the amount of hardener increases the mould hardness decreases, it is because too much hardener quantity will decrease the binding strength between resin and sand grains just like dilution effect (hardener acts as a catalyst). As setting time increases, mould hardness increases. 


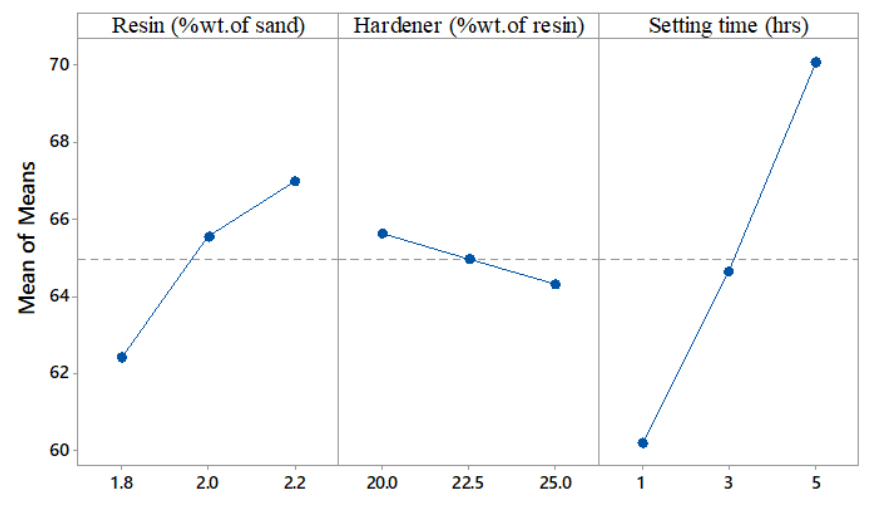

Fig. 5. Main effect plots for Means v/s factors

A surface plot of average mould hardness v/s significant factors (setting time and amount of resin) is shown in Fig. 6. As the setting time increases there will be a gradual increase in the mould hardness (In figure average value of mould hardness for 3 replicates is indicated as mean).For the same setting time, if resin content is increased within the range, there will be an increase in mould hardness. If the amount of resin is increased beyond experimental range then specimens will become wet thus getting irregularly shaped specimens. Similarly, when setting time is increased within the range with a constant level of resin, there will be an increase in mould hardness. If setting time is increased beyond the experimental range, then specimen will absorb moisture. At $2.2 \%$ of resin, there exists a point (between $4.0 \mathrm{hrs}$ to $5.0 \mathrm{hrs}$ ) where there will be a slight reduction in the average mould hardness value. Hence the relationship between the significant factors and average mould hardness value (mean1 in the graph) is non-linear.

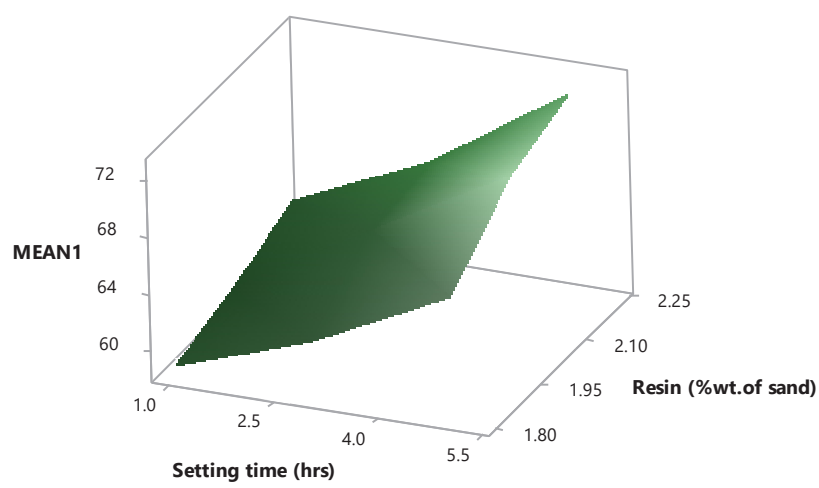

Fig. 6. Surface plot of mean response (mould hardness) v/s significant factors

\section{Conclusions}

The experimental results obtained are used to set process parameters to get maximum mould hardness in no-bake moulds to get quality castings. From the result, it can be concluded that setting time and resin are significant factors for mould hardness. The process parameters to be set to get maximum mould hardness is resin at $2.2 \%$ weight of 
sand, hardener at $20 \%$ weight of resin and setting time of $5 \mathrm{hrs}$. These values hold good for alpha set type no-bake sand moulds only and temperature condition of 250-400 Celsius.

\section{References}

1.RasikUpadhye ,Dr.Ishwar P Keswani, IJERT, 1, 1(2012).

2.R. Danko, J. Kaminska,Arch of foundry engg, 9, 33, (2009)

3.Himanshu Khandelwal,.B,Jr. of Manuf. Proc, 22,127, (2016)

4.Raghwendra Banchhor, S.K. Ganguly, IJAET,V,25,(2014).

5.M. B. Parappagoudar, D. K. Pratihar,G. L. Datta, , IJCMR,20,1, 2007

6.Dietert, H.W., Fairfield, H.H. \& Hasty, E.J,AFS Transactions, 55, 175, (1947).

7.Barlow, T.E, AFS Transactions, 74,70, (1966).

8. Frost J. Hillier M.J. AFS Transactions, 75, 126, (1967).

9.Montgomery D. C, DOE- John Wiley \& Sons, New York, (2008).

10.Patel G. M, Krishna P, and Parappagoudar M.B. Procedia Tec., 14,157 (2014).

11.GaitondeV.N, Karnik S. R, Achyutha, B.T, and Siddeswarappa, B. IJAMT,34,1 (2007).

12. Ozcelik B, and Erzurumlu T, Jr.of Materials Proc. Tech., 171(3),437, (2006).

13 .Chate G.R., Bhat R.P, \& Chate U.N. Procedia Materials Sci.. 5, 1976, (2014). 